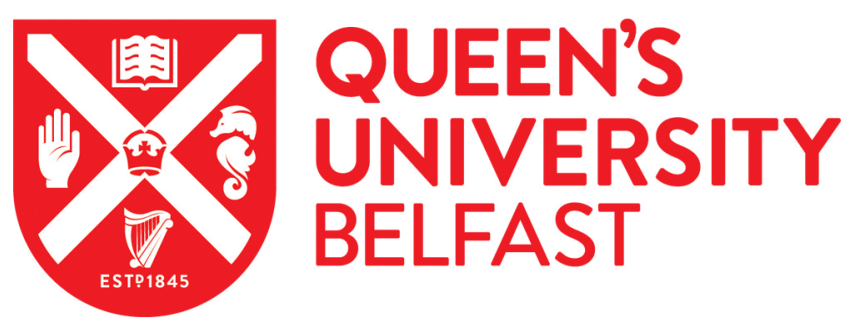

\title{
Predicting bioavailability of PAHs in soils to wheat roots with triolein- embedded cellulose acetate membranes and comparison with chemical extraction
}

Tao, Y. Q., Zhang, S. Z., Wang, Z. J., \& Christie, P. (2008). Predicting bioavailability of PAHs in soils to wheat roots with triolein-embedded cellulose acetate membranes and comparison with chemical extraction. Journal of Agricultural and Food Chemistry, 56(22), 10817-10823. https://doi.org/10.1021/jf802289q

Published in:

Journal of Agricultural and Food Chemistry

Queen's University Belfast - Research Portal:

Link to publication record in Queen's University Belfast Research Portal

\section{General rights}

Copyright for the publications made accessible via the Queen's University Belfast Research Portal is retained by the author(s) and / or other copyright owners and it is a condition of accessing these publications that users recognise and abide by the legal requirements associated with these rights.

Take down policy

The Research Portal is Queen's institutional repository that provides access to Queen's research output. Every effort has been made to ensure that content in the Research Portal does not infringe any person's rights, or applicable UK laws. If you discover content in the Research Portal that you believe breaches copyright or violates any law, please contact openaccess@qub.ac.uk. 


\title{
Predicting Bioavailability of PAHs in Soils to Wheat Roots with Triolein-Embedded Cellulose Acetate Membranes and Comparison with Chemical Extraction
}

\author{
Yuqiang Tao, ${ }^{\dagger}$ Shuzhen Zhang, ${ }^{*}{ }^{\dagger}$ ZiJian Wang, $^{\dagger}$ And Peter Christie ${ }^{*}$ \\ State Key Laboratory of Environmental Chemistry and Ecotoxicology, Research Center for \\ Eco-Environmental Sciences, Chinese Academy of Sciences, Beijing 100085, China, and Agricultural \\ and Environmental Science Department, Queen's University Belfast, Newforge Lane, \\ Belfast BT9 5PX, United Kingdom
}

\begin{abstract}
Triolein-embedded cellulose acetate membrane (TECAM) was buried in 15 field-contaminated soils in parallel with the cultivation of wheat to predict bioavailability of naphthalene, phenanthrene, pyrene, and benzo[a]pyrene to wheat roots, and the method was compared with chemical extraction methods. Although a good linear relationship was found between PAH concentrations in chemical extractants and wheat roots, the percentage of PAH in soil removed by chemical extraction was much higher than the corresponding percentage removed by wheat roots. In contrast to chemical extraction, a nearly 1:1 relationship was found between the amount of each PAH taken up by TECAMs and wheat roots $\left(r^{2}=0.798-0.925, P<0.01\right)$. Furthermore, the uptake of PAHs by TECAMs and wheat roots had the same pathway of passive transport via the soil solution. Moreover, TECAM caused minimal disturbance to the soil and was easy to deploy. Therefore, TECAM is believed to be a useful tool to predict bioavailability of PAHs to wheat roots grown in contaminated soils.
\end{abstract}

KEYWORDS: Triolein-embedded cellulose acetate membrane (TECAM); bioavailability; chemical extraction; PAHs; wheat

\section{INTRODUCTION}

Soil contamination by polycyclic aromatic hydrocarbons (PAHs) occurs widely as a result of fossil fuel combustion, wood treatment processes, automobile exhausts, and waste incineration (1). The uptake of PAHs from soil by plant roots is an important pathway for their transfer into the food chain $(2,3)$. Predicting the bioavailability of PAHs to plants in soils is therefore important for assessing crop contamination and subsequent human exposure.

In addition to the direct analysis of contaminant accumulation in plants, numerous attempts have been made to assess the bioavailability of hydrophobic organic contaminants (HOCs) to plants using chemical extraction (4-7). Previous studies have indicated that some mild, selective extractants under some specific extraction conditions are feasible to predict bioavailability of HOCs in soils to plants. However, only very limited attempts have been made in such studies to establish a statistical correlation between the extractability of HOCs and their bioavailability to plants $(4-7)$.

* Corresponding author (telephone +86-10-62849683; fax +86-1062923563; e-mail szzhang@ rcees.ac.cn.).

${ }^{\dagger}$ Chinese Academy of Sciences.

‡Queen’s University Belfast.
Lipid-containing passive samplers such as semipermeable membrane devices (SPMD) are composed of lipophilic materials and have been shown to have some potential to mimic the uptake of HOCs by living organisms (8). They have been used to predict the bioavailability of HOCs to mussels (9) and fish (10) in water. However, so far no lipid-containing passive samplers have been employed to predict the bioavailability of HOCs in soils to plants. Plant root composition, and their lipid content in particular, is believed to determine the uptake of HOCs by plant roots to a great extent, and plant root uptake of HOCs is controlled predominantly by lipid uptake $(11-13)$ because HOCs possess a strong tendency to partition into root lipids $(11-13)$. Furthermore, with the exception of a few hormone-like compounds, the uptake of HOCs by plant roots has been shown to be a passive and diffusive process (14). The uptake of HOCs by plant roots might therefore be expected to be very similar to their accumulation by lipid-containing passive samplers.

A new lipid-containing semipermeable membrane sampler, triolein-embedded cellulose acetate membrane (TECAM), has recently been developed (15). The greatest advantage of TECAM is its fast exchange kinetics: $1 \mathrm{~mL}$ of triolein is uniformly distributed on an approximately $15000 \mathrm{~cm}^{2}$ surface area of cellulose acetate, resulting in a large contact area between 
Table 1. PAH Concentrations and Soil Organic Carbon Contents $\left(f_{\circ c}\right)$ of the 15 Field-Contaminated Soils

\begin{tabular}{cccccc}
\hline soil & $\begin{array}{c}\text { Nap } \\
\left(\mu \mathrm{g} \mathrm{g}^{-1}\right)\end{array}$ & $\begin{array}{c}\text { Phe } \\
\left(\mu \mathrm{g} \mathrm{g}^{-1}\right)\end{array}$ & $\begin{array}{c}\text { Pyr } \\
\left(\mu \mathrm{g} \mathrm{g}^{-1}\right)\end{array}$ & $\begin{array}{c}\text { BaP } \\
\left(\mu \mathrm{g} \mathrm{g}^{-1}\right)\end{array}$ & $f_{\text {oc }}(\%)$ \\
\hline 1 & 0.106 & 0.083 & 0.077 & 0.024 & 1.38 \\
2 & 0.042 & 0.037 & 0.063 & 0.147 & 1.03 \\
3 & 0.143 & 0.164 & 0.399 & 0.040 & 1.51 \\
4 & 0.100 & 0.190 & 0.092 & 0.042 & 1.02 \\
5 & 0.117 & 0.165 & 0.357 & 0.060 & 1.57 \\
6 & 0.129 & 0.125 & 0.059 & 0.085 & 1.29 \\
7 & 0.085 & 0.130 & 0.054 & 0.014 & 1.41 \\
8 & 0.078 & 0.115 & 0.048 & 0.070 & 1.15 \\
9 & 0.046 & 0.091 & 0.096 & 0.041 & 1.08 \\
10 & 0.122 & 0.244 & 0.418 & 0.258 & 1.08 \\
11 & 0.132 & 0.126 & 0.054 & 0.014 & 1.58 \\
12 & 0.609 & 0.949 & 0.269 & 0.614 & 3.61 \\
13 & 0.100 & 0.140 & 0.197 & 0.132 & 1.51 \\
14 & 0.112 & 0.139 & 0.058 & 0.015 & 1.55 \\
15 & 0.150 & 0.149 & 0.082 & 0.030 & 2.01 \\
& & & & & \\
\hline
\end{tabular}

the triolein and HOCs. The aim of the present study was therefore to test the feasibility of using TECAM to predict the bioavailability of naphthalene, phenanthrene, pyrene, and benzo[a]pyrene to wheat roots grown in 15 field-contaminated soils, and the TECAM approach was also compared with several chemical extraction methods.

\section{MATERIALS AND METHODS}

Chemicals, Reagents, and TECAMs. Naphthalene (Nap, log $K_{\text {ow }}$ $=3.33)$, phenanthrene (Phe, $\left.\log K_{\text {ow }}=4.57\right)$, pyrene $\left(\mathrm{Pyr}, \log K_{\text {ow }}=\right.$ $5.13)$, and benzo $[a]$ pyrene $\left(\mathrm{BaP}, \log K_{\mathrm{ow}}=6.13\right)$ of $>99 \%$ purity were purchased from Acros Organics (Fair Lawn, NJ) and used for identification and quantification. All solvents used, that is, $n$-hexane, dichloromethane, acetone, and methanol, were of HPLC grade.

TECAMs were prepared according to the method of Xu et al. (15). They were made of cellulose acetate (17.5 wt \%, Sigma), acetone (69 wt \%), 1,4-dioxane (10 wt \%), anhydrous magnesium perchlorate (2 wt $\%)$, and triolein (1.5 wt \%, Sigma). After evaporation of acetone and 1,4-dioxane, the content of triolein in TECAM was $7.14 \mathrm{wt} \%$, the thickness of TECAM was $0.1 \mathrm{~mm}$, and the density of TECAM was $0.1 \mathrm{~mm}$ and $2.5 \mathrm{mg} \mathrm{cm}^{-2}$. The membranes were cut into $2 \mathrm{~cm} \times 3 \mathrm{~cm}$ pieces and kept in distilled water before use. Previous work indicated that there was no obvious loss or degradation of triolein in TECAMs when they were kept in distilled water or dialyzed in $n$-hexane (16).

Soil Preparation. Samples of the 15 field-contaminated soils were collected from the $5-20 \mathrm{~cm}$ depth zone of the soil profiles of agricultural fields near Tianjin city $(38.50-40.05 \mathrm{~N}, 116.51-117.83$ E) in northern China, where PAHs have accumulated in many locations as a result of coal, petroleum, and biomass combustion and wastewater irrigation over several years or decades. Each soil sample was airdried, passed through a $2 \mathrm{~mm}$ sieve, sterilized by $\gamma$-irradiation from a ${ }^{60} \mathrm{Co}$ source, and stored in brown glass containers at room temperature. Concentrations of Nap, Phe, Pyr, and $\mathrm{BaP}$ and the fraction of organic carbon $\left(f_{\text {oc }}\right)$ of the soils are shown in Table $\mathbf{1}$.

Wheat Cultivation. Wheat seeds (Triticum aestivum L., obtained from the Chinese Academy of Agricultural Sciences, Beijing, China) were first surface sterilized in $3 \% \mathrm{H}_{2} \mathrm{O}_{2}$, soaked in $2.8 \mathrm{~mol} \mathrm{~L}^{-1}$ $\mathrm{Ca}\left(\mathrm{NO}_{3}\right)_{2}$ for $4 \mathrm{~h}$, and then germinated in a cultivation dish by placing them on moist filter paper at $22-27{ }^{\circ} \mathrm{C}$. After germination, three uniform seedlings were selected and transferred to plastic pots (11 and $8 \mathrm{~cm}$ top and bottom diameters, respectively, and $10 \mathrm{~cm}$ depth) uniformly packed with $300 \mathrm{~g}$ of field-contaminated soils. The seedlings were grown under greenhouse conditions for $14 \mathrm{~h}$ at $27^{\circ} \mathrm{C}$ (day cycle) and for $10 \mathrm{~h}$ at $22{ }^{\circ} \mathrm{C}$ (night cycle). Plants were irrigated daily with distilled water to maintain soil moisture at $30 \%$. Three replicates of each soil were set up. Plants were harvested after cultivation for 45 days. Roots were washed thoroughly first with tap water and then with distilled water, wiped with clean filter paper, and weighed immediately. They were freeze-dried for $72 \mathrm{~h}$ and then reweighed to enable calculation of the water content. Dried samples were cut with stainless steel scissors and ground in a mortar to obtain homogeneous samples.

Root lipid content was determined by Soxhlet extraction with 100 $\mathrm{mL}$ of a mixed solvent of chloroform and methanol (2:1, v/v) for $24 \mathrm{~h}$. The extract was dried in a rotary evaporator, redissolved in $20 \mathrm{~mL}$ $n$-hexane, filtered through Whatman no. 5 filter paper into a preweighed glass tube to remove precipitates, and dried to a constant weight. The weight of the residue was considered to be the root lipid (17). The water content and lipid content of the roots were $82.07 \pm 1.34$ and $1.14 \pm 0.3$ wt $\%$, respectively.

TECAM Uptake. TECAM $(2 \mathrm{~cm} \times 3 \mathrm{~cm} \times 0.1 \mathrm{~mm})$ was buried in $300 \mathrm{~g}$ of soil over the wheat-growing period under the conditions described above. Four replicates of each soil were set up. TECAMs were collected from the soils after 45 days at the same time as the wheat harvest, and the time was long enough for PAHs to reach an apparent equilibrium accumulation in TECAMs (18). No obvious fouling of the membranes such as the deposition or growth of microorganisms on the membrane and no loss of triolein were observed during this period.

Soil Extraction. Ten grams of soil and $10 \mathrm{~mL}$ of water or $50 \%$ methanol solution or $n$-butanol or $n$-hexane/dichloromethane $(1: 1 \mathrm{v} / \mathrm{v})$ were added to $50 \mathrm{~mL}$ centrifuge bottles, and the centrifuge bottles were then placed on a reciprocating shaker at $100 \mathrm{rpm}$ for $48 \mathrm{~h}$ at room temperature in the dark. The samples were centrifuged at $10000 \mathrm{~g}$ for $30 \mathrm{~min}$, and the supernatants were collected and filtered through a 0.45 $\mu \mathrm{m}$ filter. Five milliliters of each filtrate was extracted with $n$-hexane $(5 \mathrm{~mL} \times 3)$. The extracts were dehydrated with $3-5 \mathrm{~g}$ of anhydrous sodium sulfate, evaporated, solvent-exchanged into methanol $(0.2 \mathrm{~mL})$, and stored prior to analysis.

Measurement of PAHs in Soil Solution. Ten grams of each soil and $10 \mathrm{~mL}$ of distilled water were added to a $50 \mathrm{~mL}$ centrifuge bottle [the soil to water ratio was discussed by Ter Laak et al. $(19,20)$ ], and the centrifuge bottles were placed in the dark at room temperature for 7 days without agitation. They were then centrifuged at $10000 \mathrm{~g}$ for 30 min, and the supernatants were collected and filtered through a 0.45 $\mu \mathrm{m}$ filter. Five milliliters of each filtrate was extracted with $n$-hexane $(5 \mathrm{~mL} \times 3)$. The extracts were dehydrated with $3-5 \mathrm{~g}$ of anhydrous sodium sulfate, evaporated, solvent-exchanged into methanol $(0.2 \mathrm{~mL})$, and stored prior to analysis.

Chemical Analysis. Triplicate subsamples of wheat roots were collected. Each root subsample ( $0.1 \mathrm{~g}$ dry weight) was thoroughly mixed with $1-2 \mathrm{~g}$ of anhydrous sodium sulfate, loaded into a Soxhlet thimble, and extracted with $100 \mathrm{~mL}$ of $n$-hexane/dichloromethane $(1: 1 \mathrm{v} / \mathrm{v})$ at $60{ }^{\circ} \mathrm{C}$ for $24 \mathrm{~h}$. The extract was reduced to about $5 \mathrm{~mL}$ with a rotary evaporator, purged to about $1-2 \mathrm{~mL}$ under a gentle nitrogen stream, and then cleaned with a Florisil SPE $(1 \mathrm{~g} / 6 \mathrm{~mL})$ and eluted with $6 \mathrm{~mL}$ of $n$-hexane/dichloromethane $(4: 1 \mathrm{v} / \mathrm{v})$. The eluates were evaporated, solvent-exchanged into methanol $(1.00 \mathrm{~mL})$, and stored prior to analysis.

TECAM samples were rinsed with distilled water, wiped with clean filter paper, dialyzed in $20 \mathrm{~mL}$ of $n$-hexane for $24 \mathrm{~h}$, and rinsed with $n$-hexane $(1 \mathrm{~mL} \times 3)$. All of the solutions were combined together. Dialysis solutions of TECAMs were evaporated under a gentle nitrogen stream, solvent-exchanged into methanol $(1.0 \mathrm{~mL})$, and stored prior to analysis. TECAMs were stable in $n$-hexane, with negligible weight loss of triolein or cellulose acetate during dialysis, and therefore no cleanup of the samples was required.

PAHs in samples were analyzed by HPLC-FLD (Agilent 1200 series). Chromatographic separation and resolution were optimized by using a LiChrospher (Merck, Darmstadt, Germany) reverse-phase $\mathrm{C}_{18}$ column $(4.6 \times 150 \mathrm{~mm}, 5 \mu \mathrm{m}$ particle size $)$ specific for PAH analysis. The mobile phase was methanol/water $(0-11 \mathrm{~min}$, from $80 / 20$ to $90 /$ $10 \%$; 11-18 min, $90 \% / 10 \%$ ), and the $\mathrm{C}_{18}$ column was kept at $25^{\circ} \mathrm{C}$. The excitation wavelength of Nap, Phe, Pyr, and $\mathrm{BaP}$ was $260 \mathrm{~nm}$. The emission wavelength of Nap and Phe was $350 \mathrm{~nm}$, and that of Pyr and $\mathrm{BaP}$ was $420 \mathrm{~nm}$.

Solvent, TECAM, and root controls were included. Extraction recoveries of Nap, Phe, Pyr, and BaP in TECAM were determined by adding the standard solution of these PAHs at seven different concentrations into the solvent mixture of $60 \mathrm{~mL}$ of acetone and $5 \mathrm{~mL}$ of 1,4-dioxane during the TECAM preparation, and the recoveries were $85.2 \pm 2.1,88.7 \pm 1.9,89.4 \pm 2.7$, and $93.5 \pm 2.8 \%$, respectively. 

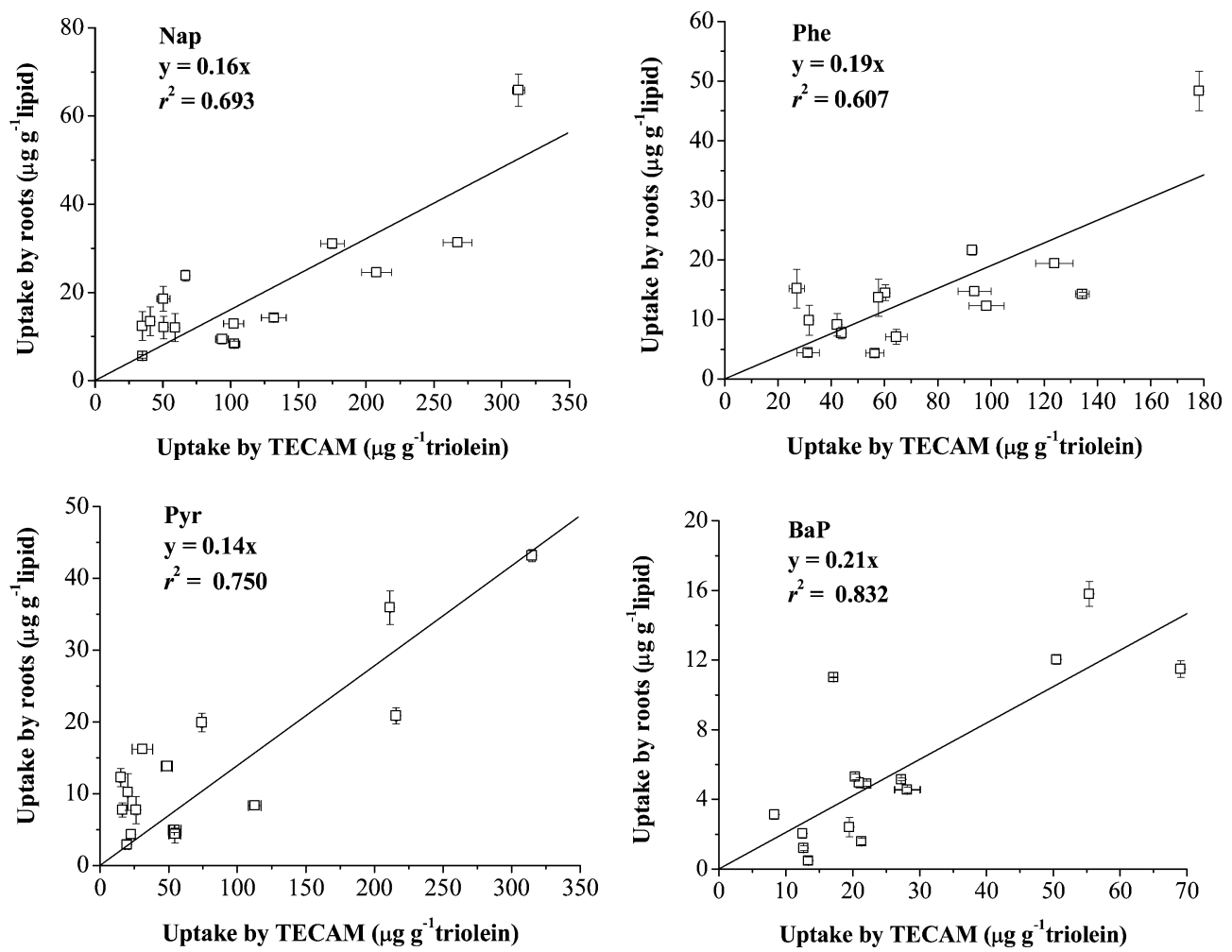

Figure 1. Relationship between concentrations of PAHs taken up by wheat roots and TECAMs from field-contaminated soils on a lipid basis $(n=15$, $P<0.01)$.

Extraction recoveries of Nap, Phe, $\mathrm{Pyr}$, and $\mathrm{BaP}$ in roots were $87.3 \pm$ $2.7,94.3 \pm 1.9,90.5 \pm 2.2$, and $87.3 \pm 1.8 \%(n=7)$, respectively.

\section{RESULTS}

Concentrations of Nap, Phe, Pyr, and $\mathrm{BaP}$ in the 15 soils $\left(C_{\text {soil }}\right)$ ranged from 0.014 to $0.949 \mu \mathrm{g} \mathrm{g}^{-1}$ (Table 1). PAH concentrations in the soils remained virtually unchanged after wheat cultivation and TECAM exposure. The amounts of Nap, Phe, Pyr, and $\mathrm{BaP}$ accumulated in TECAM accounted for only $0.27 \pm 0.03,0.16 \pm 0.01,0.21 \pm 0.03$, and $0.33 \pm 0.08 \%$ of the amounts of each PAH in the $300 \mathrm{~g}$ of soil in each pot $(n=$ 15 ), these values being fairly close to the $0.23 \pm 0.02,0.16 \pm$ $0.02,0.27 \pm 0.03$, and $0.32 \pm 0.08 \%$ ratios of the uptake by wheat roots to their amounts in soils. After lipid normalization, the concentrations of PAHs in TECAMs exposed to the soils were found to have a significant linear relationship with the corresponding concentrations in wheat roots grown in the same soils (Figure 1, $r^{2}=0.607-0.832, P<0.01$ ). The slopes in Figure 1 could be referred to as the average ratio of $\mathrm{PAH}$ concentration in roots to that in TECAMs; these ratios were $0.11,0.13,0.10$, and 0.14 for Nap, Phe, Pyr, and BaP, respectively. The amount of each $\mathrm{PAH}$ taken up by wheat roots in each pot was further calculated and plotted against the amount accumulated by TECAMs, which were buried in the same amount of soils (300 g) separately under the same cultivation conditions for wheat. A significant correlation was found between them for all of the PAHs (Figure 2, $n=15, P<0.01$ ). The average ratios of the uptake by wheat roots to that by TECAMs were $0.80,1.03,1.22$, and 0.99 for Nap, Phe, Pyr, and $\mathrm{BaP}$, respectively, which closely approximated to 1 . The amounts of PAH taken up by TECAMs from soils were therefore very close to those taken up by wheat roots.

Concentrations of Nap, Phe, Pyr, and $\mathrm{BaP}$ in the soil solution ranged from 1.71 to 29.15 , from 0.08 to 0.63 , from 0.06 to 0.66 , and from $3.53 \times 10^{-4}$ to $13.9 \times 10^{-4} \mu \mathrm{g} \mathrm{L}^{-1}$, respectively.
Concentrations of PAHs in both wheat roots and TECAMs were found to correlate well with their concentrations in soil solution (Figures 3 and 4, $n=15, P<0.01$ ). Previous work has indicated that 45 days was long enough for PAHs to achieve apparent equilibrium accumulation in TECAM. Without consideration of the dilution of PAHs in wheat roots due to the very limited acropetal transport, it is reasonable to assume that PAH uptake by roots can achieve a temporary steady state after 45 days of growth. Thus, the slopes in Figures 3 and $\mathbf{4}$ can be referred to as the average root concentration factor (RCF) and membrane concentration factor (MCF), respectively. Both the $\log$ RCF and $\log$ MCF values had significant linear relationships with $\log K_{\text {ow }}$ (Figure 5, $P<0.05$ ).

The concentrations of PAHs extracted by different extractants followed the order $n$-hexane/dichloromethane $(1: 1 \mathrm{v} / \mathrm{v})>$ $n$-butanol $>50 \%$ methanol solution, water (Figure 6). Percentages of PAHs in soil removed by the chemical extractants are listed in Table 2 and compared with those removed by wheat roots and TECAM. For all of the extractants a good linear relationship was found between the extractable concentrations of PAHs in soils and the PAH concentrations in wheat roots. The concentration and percentage of each $\mathrm{PAH}$ extracted increased with increasing hydrophobicity of the extractants from water to $n$-hexane/dichloromethane $(1: 1 \mathrm{v} / \mathrm{v})$.

\section{DISCUSSION}

Significant correlations existed between the concentrations of PAHs in wheat roots and TECAMs. However, PAH concentrations in TECAMs were about 40 times higher than in roots. Plant roots are composed of large amounts of water and smaller amounts of lipids and polar organic components such as cellulose, carbohydrates, and proteins. Root lipids have been demonstrated in numerous studies $(11-14)$ to play a key role in the uptake of HOCs by plant roots. Chiou et al. (12) reported 

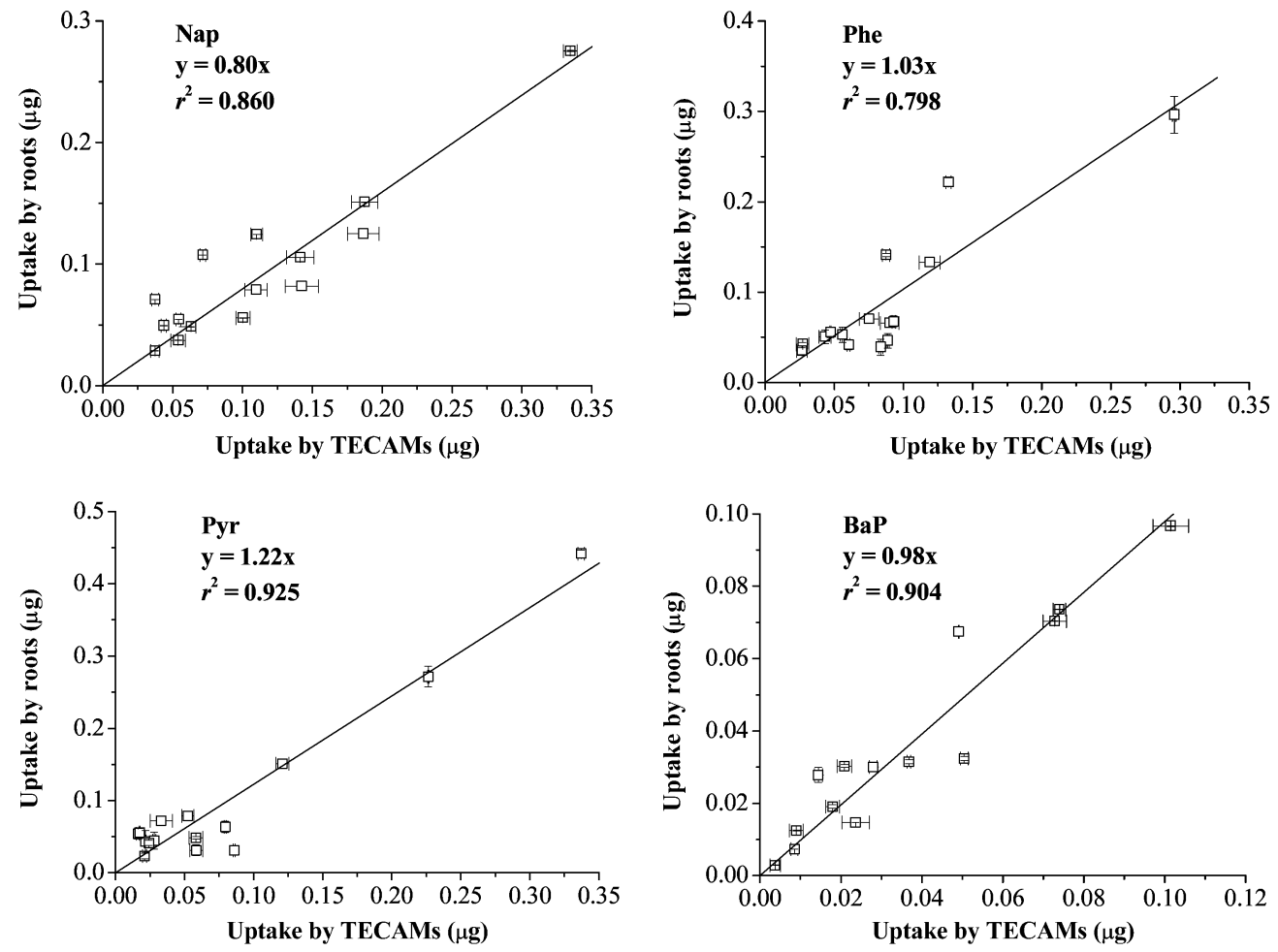

Figure 2. Correlation between uptake of PAHs by wheat roots and $6 \mathrm{~cm}^{2}$-TECAM $(0.015 \mathrm{~g}$ dry weight) cultivated in $300 \mathrm{~g}$ of each soil in parallel under the same conditions $(n=15, P<0.01)$.
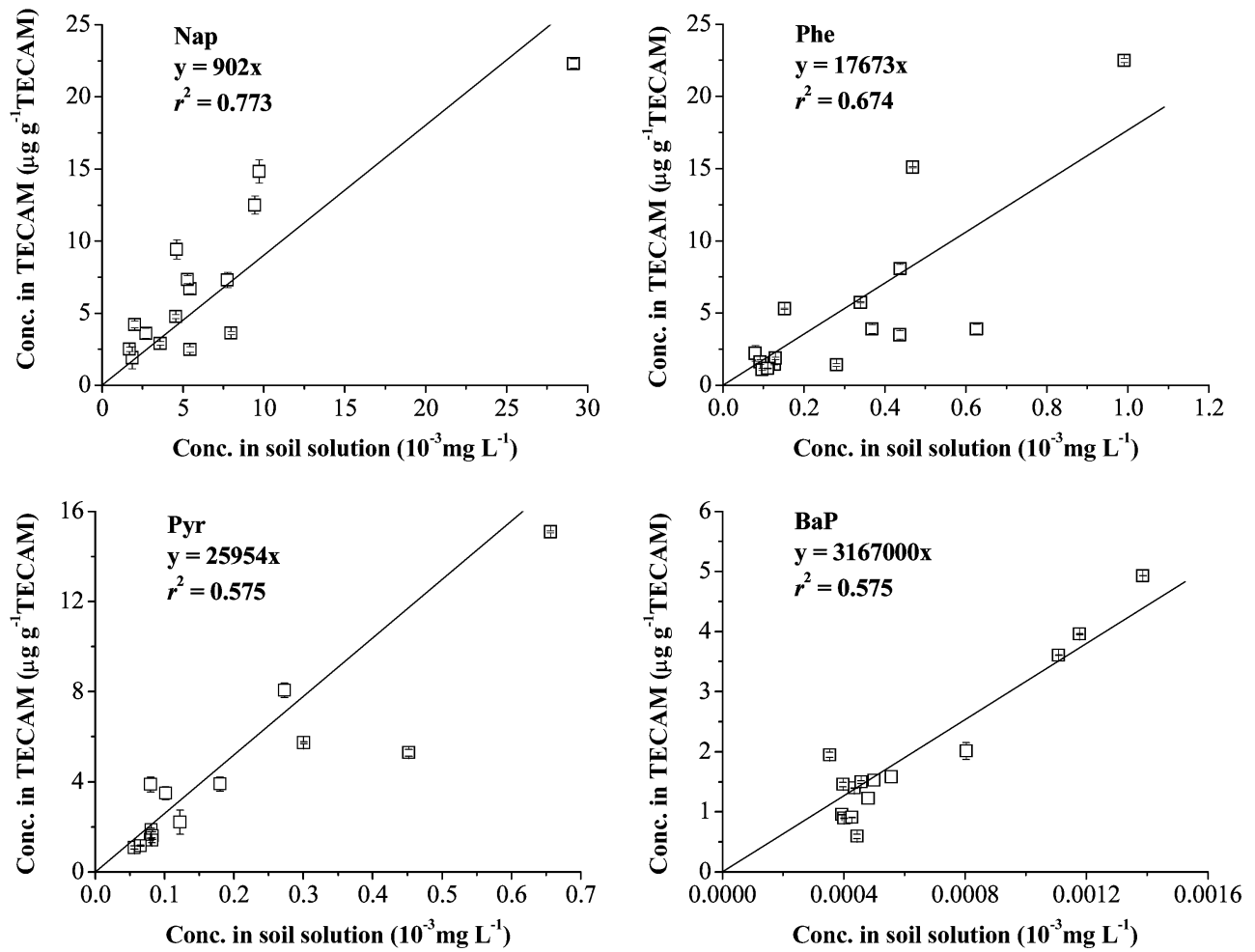

Figure 3. Relationship between concentrations of PAHs in wheat roots and soil solutions $(n=15, P<0.01)$.

that for HOCs with $\log K_{\mathrm{ow}}>3.0$ the partition contribution of water and polar organic components became unimportant relative to that of root lipids. For HOCs with $\log K_{\text {ow }}>3.0$ the partition contribution of cellulose acetate also becomes unimportant relative to that of triolein due to its high polarity. Concentrations of PAHs in wheat roots and TECAMs were therefore lipid normalized (Figure 1). Although PAH concentrations in wheat roots and TECAMs became closer to each other after lipid normalization, concentrations of PAHs in wheat roots were still much lower than in TECAMs as illustrated by the average ratios of concentration in roots to TECAMs. This may be due to the different components and physicochemical properties of root lipids and triolein in TECAMs. Dilution of PAHs in wheat roots due to the potential acropetal transport could be another explanation. However, the amount of each $\mathrm{PAH}$ taken up by wheat roots was found to be very close to the 

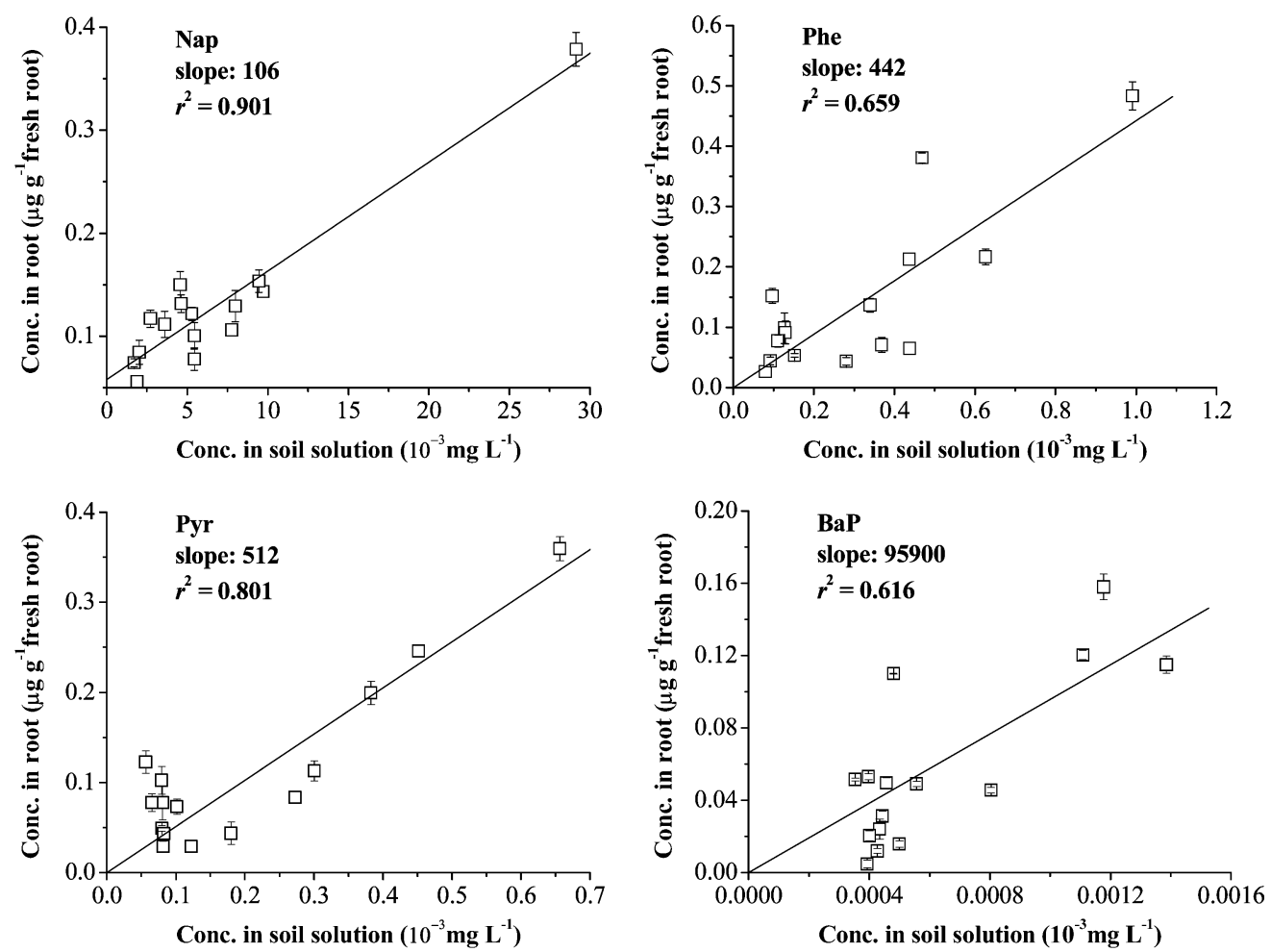

Figure 4. Correlation between concentrations of PAHs in TECAMs and soil solutions $(n=15, P<0.01)$.
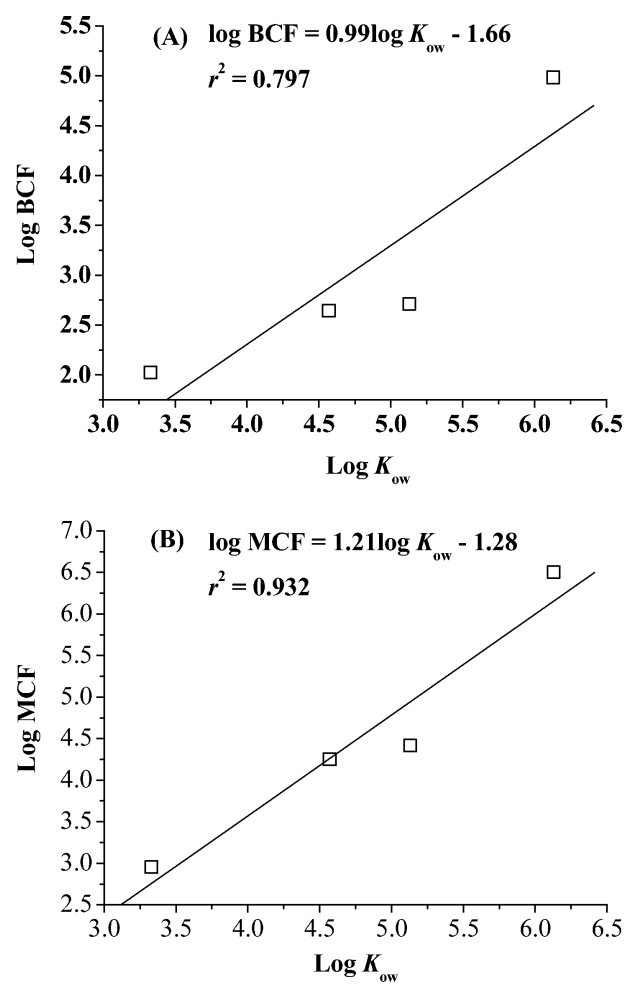

Figure 5. Relationship between membrane concentration factor (MCF) $(A)$, root concentration factor $(\mathrm{RCF})(\mathrm{B})$, and $K_{\text {ow }}$ of PAHs $(P<0.01)$.

quantity of PAH removed from soils by TECAMs tested in parallel under the same conditions (Figure 2). It is reasonable to consider the amount of PAH taken up by roots to be the apparent bioavailable fraction in soil, and these results indicate that TECAM can be used to predict bioavailability of PAHs to wheat roots.

The concentrations of PAHs in roots and TECAMs were noted to be proportional to the corresponding concentrations in the soil solutions with a little scatter $(n=15, P<0.01)$ (Figures 3 and 4). This suggests that PAHs in soil solution represent the main source of PAHs in soils taken up by both wheat roots and TECAMs, and the difference in PAH concentrations between wheat roots or TECAMs and the surrounding solution may be one of the major driving forces for the uptake of PAHs. A good relationship between $\log \mathrm{RCF}$ or $\log \mathrm{MCF}$ and $\log K_{\text {ow }}$ (Figure 5) indicates that the uptake of PAHs in soils by both wheat roots and TECAMs depends on the hydrophobicity of the compounds. The hydrophobicity of these PAHs may be another driving force for their uptake by wheat roots and TECAMs. These two driving forces suggest that uptake of PAHs in soils by both wheat roots and TECAMs is a passive process. Passive transport via soil solution is therefore the main pathway of uptake of PAHs in soils by both wheat roots and TECAMs. Data scatter shown in Figures $\mathbf{3}$ and $\mathbf{4}$ could result from the differences in soil physicochemical properties and the diverse sources and histories of PAHs in the soils because very similar results were obtained for the multiple runs of each soil sample as the data errors showed.

Attempts have been made to predict bioavailability of HOCs to plants by establishing a statistical correlation between extractable concentrations with different chemical extractants and their accumulation in plants (4-7). As the results show in Table 2, although good linear relationships were found between the concentrations of PAH in the extractants and plant roots, the percentages of PAH in soil removed by the chemical extractants were much higher than the corresponding percentage of PAH removed by plant roots. Only the HOCs in rhizosphere soil rather than in bulk soil are considered to be available for root uptake (21). Extractability calculated on the basis of the whole soil will definitely overestimate the bioavailability of HOC to plant roots. Moreover, treatment of the soil with chemical extractants is likely to affect soil structure in contrast to PAH uptake by wheat roots. Although Tang and Alexander (4) observed that uptake of aged and unaged anthracene by wheat and barley was correlated with the amounts extracted by 

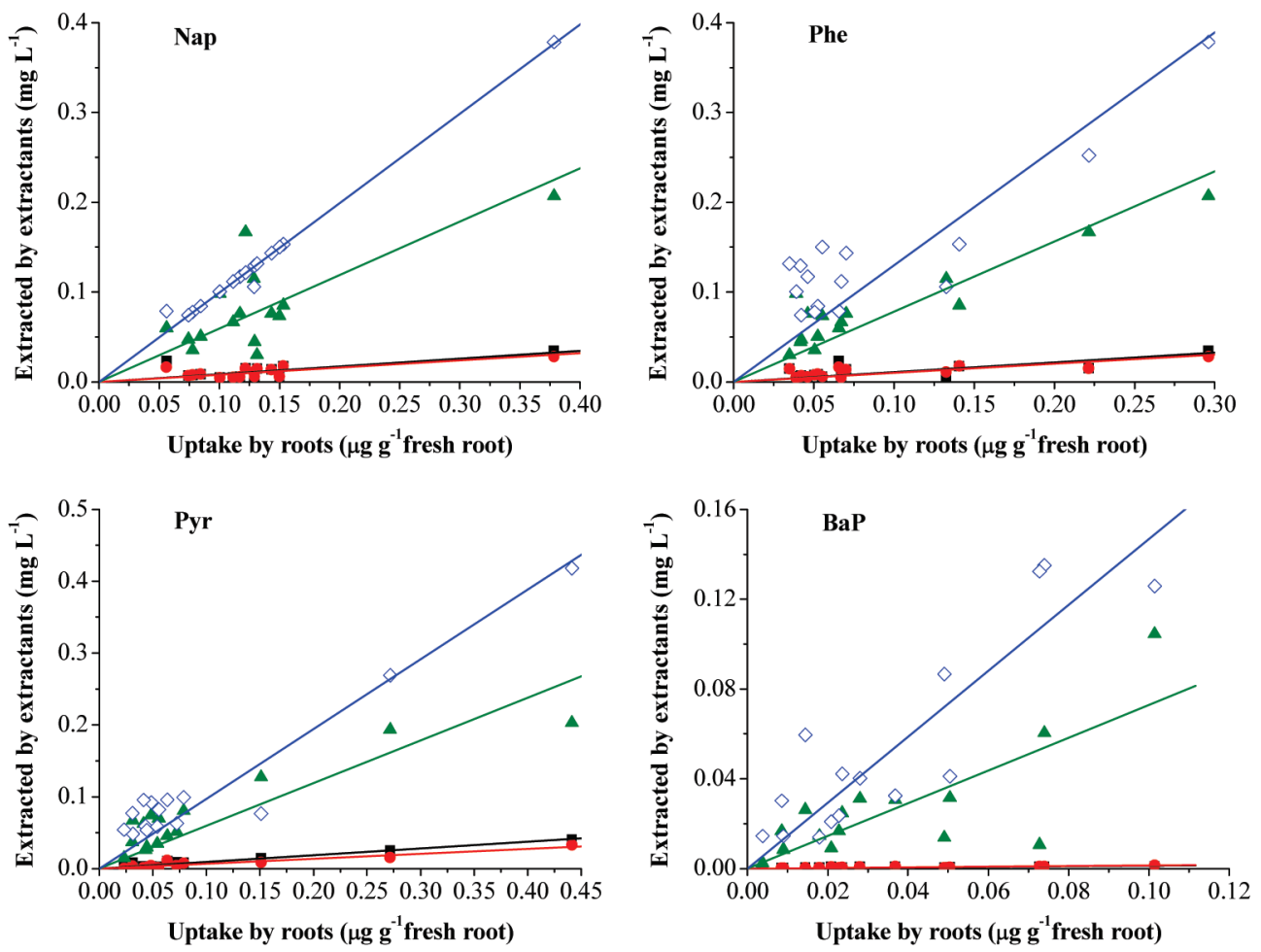

Figure 6. Correlations between concentrations of PAHs extracted by chemical extractants and uptake by wheat roots from the same soils $(n=15, P$

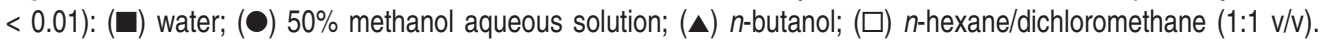

Table 2. Percentage of PAH in Soil Removed by Wheat Roots, TECAM, and Chemical Extractants

\begin{tabular}{lrrrr}
\hline & Nap (\%) & Phe (\%) & \multicolumn{1}{c}{ Pyr (\%) } & \multicolumn{1}{c}{ BaP (\%) } \\
\hline wheat roots & $0.23 \pm 0.02$ & $0.16 \pm 0.02$ & $0.27 \pm 0.03$ & $0.32 \pm 0.08$ \\
TECAM & $0.27 \pm 0.03$ & $0.16 \pm 0.01$ & $0.21 \pm 0.03$ & $0.33 \pm 0.08$ \\
water & $8.45 \pm 0.79$ & $5.45 \pm 0.46$ & $5.10 \pm 0.47$ & $1.23 \pm 0.11$ \\
50\% methanol & $8.80 \pm 0.67$ & $5.16 \pm 0.43$ & $3.66 \pm 0.27$ & $1.17 \pm 0.07$ \\
n-butanol & $55.10 \pm 3.73$ & $44.30 \pm 3.07$ & $53.77 \pm 4.28$ & $52.23 \pm 4.73$ \\
n-hexane/DCM & $96.77 \pm 3.15$ & $96.83 \pm 6.03$ & $86.06 \pm 7.50$ & $88.75 \pm 5.98$
\end{tabular}

mild extraction with $n$-butanol, in the present study the percentage of all four PAHs extracted by $n$-butanol was 163.2-276.9 times as much as that taken up by wheat roots. This may be due to the different extraction conditions and ratios of extractants to soil used by Tang and Alexander and the present study. In addition, with increasing hydrophobicity of the extractants from water to $n$-hexane/dichloromethane (1:1 $\mathrm{v} / \mathrm{v})$, the extractable concentration and percentage of each PAH extracted increased (Figure 6). Therefore, different extractants and even the same extractant under different extraction conditions or different extractant-to-soil ratios will result in different results so that the results of different studies are difficult to compare.

In contrast to extraction with chemical extractants, the uptake of each PAH by $6 \mathrm{~cm}^{2}$-TECAMs was very close to that by wheat roots. Compared to chemical extraction methods, predicting the bioavailability of HOCs in soil is easier to carry out by burying TECAM in soils in parallel with wheat growth under the same conditions. The time needed for the apparent equilibrium sampling of PAHs by TECAMs is much shorter than that for plant cultivation. The water-to-soil ratio of $30 \%$ used for TECAM sampling matches the field soil moisture content, which provides potential field application of TECAM. Moreover, the average percentages of the uptake of each PAH by $6 \mathrm{~cm}^{2}$ TECAM to the amounts of Nap, Phe, Pyr, and BaP in $300 \mathrm{~g}$ of field-contaminated soil were only $0.27 \pm 0.03,0.16 \pm 0.01$,
$0.21 \pm 0.03$, and $0.33 \pm 0.08 \%(n=15)$, respectively, and the amount of each PAH in soils remained virtually unchanged after TECAM burial. This suggests that the uptake of PAHs by TECAMs causes minimum disturbance and is nearly nondestructive to soil, which is similar to uptake by wheat roots. In addition, uptake of PAHs by TECAMs and wheat roots has approximately the same pathway (passive transport via the soil solution). TECAMs may therefore be more suitable and easier than chemical extraction methods to predict the bioavailability of PAHs to wheat roots grown in soils.

\section{LITERATURE CITED}

(1) Wilson, S. C.; Jones, K. C. Bioremediation of soil contaminated with polynuclear aromatic hydrocarbons (PAHs): a review. Environ. Pollut. 1993, 81, 229-249.

(2) McKone, T. E.; Ryan, P. B. Human exposures to chemicals through food chains: an uncertainty analysis. Environ. Sci. Technol. 1989, 23, 1154-1163.

(3) McLachlan, M. S. Bioaccumulation of hydrophobic chemicals in agricultural food chains. Environ. Sci. Technol. 1996, 30, 252259.

(4) Tang, J. X.; Alexander, M. Mild extraction and bioavailability of polycyclic aromatic carbons in soils. Environ. Toxicol. Chem. 1999, 18, 2711-2714.

(5) Tao, S.; Xu, F.; Liu, W.; Cui, Y.; Coveney, R. M. A chemical extraction method for mimicking bioavailability of polycyclic aromatic hydrocarbons to wheat grown in soils containing various amounts of organic matter. Environ. Sci. Technol. 2006, 40, 22192224.

(6) Tao, S.; Guo, L. Q.; Wang, X. J.; Liu, W. X.; Ju, T. Z.; Dawson, R.; Cao, J.; Xu, F. L.; Li, B. G. Use of sequential ASE extraction to evaluate the bioavailability of DDT and its metabolites to wheat in soils with various organic carbon content. Sci. Total Environ. 2004, 320, 1-9.

(7) Bogolte, B. J.; Ehlers, G. A. C.; Braun, R.; Loibner, A. P. Estimation of PAH bioavailability to Lepidium sativum using sequential supercritical fluid extraction-a case study with industrial contaminated soils. Eur. J. Soil Biol. 2007, 43, 242-250. 
(8) Huckins, J. N.; Tubergen, M. W.; Manuweera, G. K. Semipermeable membrane devices containing model lipid: A new approach to monitoring the bioavailability of lipophilic contaminants and estimating their bioconcentration potential. Chemosphere 1990, 20, 533-552.

(9) Gourlay, C.; Miege, C.; Noir, A.; Ravelet, C.; Garric, J.; Mouchel, J. How accurately do semi-permeable membrane devices measure the bioavailability of polycyclic aromatic hydrocarbons to Daphnia magna. Chemosphere 2005, 61, 1734-1739.

(10) Verweij, F.; Booij, K.; Satumalay, K.; Van Der Molen, N.; Van Der Oost, R. Assessment of bioavailable PAH, PCB and OCP concentrations in water, using semipermeable membrane devices (SPMDs), sediments and caged carp. Chemosphere 2004, 54, 1675-1689.

(11) Briggs, G. G.; Bromilow, R. H.; Evans, A. A. Relationships between lipophilicity and root uptake and translocation of nonionised chemicals by barley. Pestic. Sci. 1982, 13, 495-504.

(12) Chiou, C. T.; Sheng, G.; Manes, M. A partition-limited model for the plant uptake of organic contaminants from soil and water. Environ. Sci. Technol. 2001, 35, 1437-1444.

(13) Simonich, S. T.; Hites, R. A. Organic pollutant accumulation in vegetation. Environ. Sci. Technol. 1995, 29, 2905-2913.

(14) Bromilow, R. H.; Chamberlain, K. Principles governing uptake and transport of chemicals. In Plant Contamination: Modeling and Simulation of Organic Chemicals Processes; Trapp, S., Mcfarlane, J. C., Eds.; Lewis Publishers: London, U.K., 1995; pp 38-64.

(15) Xu, Y.; Wang, Z.; Ke, R.; Khan, S. Accumulation of organochlorine pesticides from water using triolein-embedded cellulose acetate membranes. Environ. Sci. Technol. 2005, 39, 1152-1157.
(16) Xu, Y.; Lü, Y.; Li, J.; Ma, M.; Wang, Z. The research on the preparation and foundmental properties of a new type of cellulose acetate composite membrane. Chinese High Technol. Lett. 2004, $1,89-94$.

(17) Li, H.; Sheng, G.; Chiou, C.; Xu, O. Relation of organic contaminant equilibrium sorption and kinetic uptake in plant. Environ. Sci. Technol. 2005, 39, 4864-4870.

(18) Tao, Y.; Zhang, S.; Wang, Z.; Christie, P. Predicting bioavailability of PAHs in field-contaminated soils by passive sampling with triolein embedded cellulose acetate membranes. Environ. Pollut. (in press).

(19) Ter Laak, T. L.; Agbo, S. O.; Barendrent, A.; Hermens, J. L. M. Freely dissolved concentrations of PAHs in soil pore water: measurement via solid-phase extraction and consequences for soil tests. Environ. Sci. Technol. 2006, 40, 1307-1313.

(20) Ter Laak, T. L.; Barendrent, A.; Hermens, J. L. M. Freely dissolved concentrations and sorption coefficients of PAHs in spiked, aged, and field-contaminated soils. Environ. Sci. Technol. 2006, 40, 2184-2190.

(21) Wu, N.; Zhang, S.; Huang, H.; Christie, P. Enhanced dissipation of phenanthrene in spiked soil by arbuscular mycorrhizal alfalfa combined with a non-ionic surfactant amendment. Sci. Total Environ. 2008, 394, 230-236.

Received for review July 25, 2008. Revised manuscript received September 18, 2008. Accepted September 19, 2008. This work was funded by the National Natural Science Foundation of China (Projects 40730740 and 20621703) and the Knowledge Innovation Program of the Chinese Academy of Sciences (Grant kzcx1-yw-06-03).

JF802289Q 